\title{
Knowledge and Perception of Stroke: A Population-Based Survey in Uganda
}

\author{
Jane Nakibuuka, ${ }^{1}$ Martha Sajatovic, ${ }^{2}$ Elly Katabira, ${ }^{1}$ Edward Ddumba, ${ }^{3}$ \\ Jayne Byakika-Tusiime, ${ }^{4}$ and Anthony J. Furlan ${ }^{5}$ \\ ${ }^{1}$ Department of Medicine, School of Medicine, Makerere University College of Health Sciences, P.O. Box 7051, Kampala, Uganda \\ ${ }^{2}$ Neurological and Behavioral Outcomes Center, University Hospitals Case Medical Center, 11100 Euclid Avenue, \\ Cleveland, OH 44106, USA \\ ${ }^{3}$ Department of Medicine, St Raphael of St Francis Nsambya Hospital, Nkozi University, P.O. Box 7146, Kampala, Uganda \\ ${ }^{4}$ Department of Epidemiology and Biostatics, School of Public Health, Makerere University College of Health Sciences, \\ P.O. Box 7072, Kampala, Uganda \\ ${ }^{5}$ University Hospitals Case Medical Center, Neurological Institute Case Western Reserve University, 11100 Euclid Avenue, \\ Cleveland, $\mathrm{OH} 44106$, USA
}

Correspondence should be addressed to Jane Nakibuuka; nakibuukajm@yahoo.com

Received 19 February 2014; Accepted 24 March 2014; Published 6 April 2014

Academic Editors: H. McNaughton and M. Paciaroni

Copyright (C) 2014 Jane Nakibuuka et al. This is an open access article distributed under the Creative Commons Attribution License, which permits unrestricted use, distribution, and reproduction in any medium, provided the original work is properly cited.

\begin{abstract}
Purpose. This study, designed to complement a large population survey on prevalence of stroke risk factors, assessed knowledge and perception of stroke and associated factors. Methods. A population survey was conducted in urban Nansana and rural Busukuma, Wakiso district, central Uganda. Adult participants selected by multistage stratified sampling were interviewed about selected aspects of stroke knowledge and perception in a pretested structured questionnaire. Results. There were 1616 participants (71.8\% urban; $68.4 \%$ female; mean age: 39.6 years \pm 15.3 ). Nearly $3 / 4$ did not know any stroke risk factors and warning signs or recognize the brain as the organ affected. Going to hospital (85.2\%) was their most preferred response to a stroke event. Visiting herbalists/traditional healers was preferred by less than 1\%. At multivariable logistic regression, good knowledge of stroke warning signs and risk factors was associated with tertiary level of education (OR 4.29, 95\% CI 2.13-8.62 and OR 5.96, 95\% CI 2.94-12.06), resp.) and self-reported diabetes (OR 1.97, 95\% CI 1.18-3.32 and OR 1.84, 95\% CI 1.04-3.25), resp.). Conclusion. Knowledge about stroke in Uganda is poor although the planned response to a stroke event was adequate. Educational strategies to increase stroke knowledge are urgently needed as a prelude to developing preventive programmes.
\end{abstract}

\section{Introduction}

Stroke is one of the leading causes of mortality and morbidity worldwide [1-4] with developing countries accounting for $85 \%$ of global deaths from stroke [1-3]. Lack of information and poor control of stroke risk factors contribute to the rising incidence of stroke amongst Africans [5-7]. The success of primary preventive measures and timely medical attention immediately following a stroke is influenced by the public's knowledge and perception of stroke and its risk factors [6, 810]. The few studies done in Africa to assess the knowledge of stroke among health workers, stroke patients, carers of stroke patients, and the general population have reported low levels of knowledge about recognizing and preventing stroke [6, 812]. Published studies from Africa note that stroke-like symptoms may be considered both physical and social conditions resulting from natural or environmental causes and supernatural causes such as demons and witchcraft [13-15]. Health care access is strongly influenced by cultural knowledge and interpretation of disease symptoms [16, 17], structural and gender constraints [17, 18], and trust in providers [19]. In Uganda, public perception and level of knowledge of stroke warning signs and risk factors have not been well studied. Given the close relationship between health behaviours and health knowledge, this study assessed the knowledge and perception of stroke (organ focus, risk factors, warning signs, 
treatment choice, availability of sources of information, and perceived risk) among urban and rural populations in Wakiso district, central Uganda. This information is critical to inform appropriate health promotion campaigns to prevent stroke and minimise acute stroke complications among high risk populations.

\section{Materials and Methods}

This was a cross sectional study within an existing population survey of 5481 participants on prevalence of stroke risk factors in Wakiso district. Face to face interviews were conducted between August 2012 and August 2013. Multistage stratified sampling technique was used as described below. At the subcounty level, urban Nansana town council was randomly selected out of 5 urban subcounties and rural Busukuma subcounty was randomly selected out of 13 rural subcounties in Wakiso district. Mapping of the selected urban and rural areas followed by a household census identified 25 villages with 26,575 households in Nansana town council and 48 villages with 13,091 households in Busukuma subcounty. The sampling frame was all households in these areas. Systematic sampling was used to select households in each village to total 4,023 in the urban area and 1458 in the rural area that would participate in the large population survey. One adult, randomly selected from each household and consented, participated in the study. The selected households were visited by the research team. The randomly selected participant was informed about the research and the intended use of the information obtained. A request for a written informed consent was then sought. Consented participants presented to the selected health facility the following morning from where they were interviewed in English or the local language by trained survey staff; blood pressure and anthropometric measurements were taken and blood samples for HIV, fasting blood sugar, fasting lipid profile, and rapid plasma reagin tests were provided. Out of the 4023 participants in the urban area and 1458 in the rural area, systematic sampling was used to select 1161 and 455 participants from the urban and rural areas, respectively, to be interviewed on selected aspects of stroke knowledge and perception. Ethical approval for the study was obtained from Makerere University College of Health Sciences' School of Medicine review board and ethics committee. Written informed consent was obtained before enrolling the participants into the study.

2.1. Questionnaire. Selected aspects of stroke knowledge and perceptions were obtained using a pretested and standardised questionnaire with options for multiple responses. Following extensive literature search, the questionnaire was constructed and modified from research by Sug Yoon et al. [20], Ayanniyi et al. [9], Borhani Haghighi et al. [11], and Akinyemi et al. [6] to evaluate knowledge and perception of stroke in an Australian urban population, among adults in Osogbo, Nigeria, and Iranian population, among hospital workers in an African community, respectively. The questionnaire evaluated selected sociodemographic characteristics: perceptions of stroke, what they believe causes a stroke; planned response to a stroke event and concern about having a stroke; basic knowledge of stroke: organ affected, if stroke is preventable, recurrence of a stroke, and effect of stroke on daily activities; knowledge of stroke warning signs and risk factors; sources of information about stroke. Participant's knowledge of stroke warning signs was categorized based on the numbers of stroke warning signs $[9,21]$. Individuals with good knowledge could identify 5-10 stroke warning signs, fair knowledge 2-4 signs, and poor knowledge one stroke warning sign. A similar categorization was used for participant's knowledge of stroke risk factors.

2.2. Statistical Analysis. Descriptive statistics of mean, frequency, and percentages were used to summarise data on sociodemographic variables and stroke knowledge and perceptions. Chi-square tests were used to assess associations between stroke knowledge and perception and demographic variables and self-reported risk factors. Logistic regression was used to determine predictors of knowing the organ affected by stroke and good level of knowledge of stroke warning signs and risk factors. All tests of hypothesis were two tailed with a level of significance at 0.05. All statistical analysis was performed using STATA software version 12 .

\section{Results}

A total of 1616 adults, 1161 (71.8\%) from the urban area $(71.9 \%$ females; mean age 38.8 years \pm 14.8$)$ and $455(28.2 \%)$ from the rural area $(59.6 \%$ females; mean age 43.0 years \pm 17.1 ), participated in the study. There was a significant difference in proportions between urban and rural participants regarding male sex $P=0.004$, female sex $P<0.001$, Protestant religion $P=0.028$, Muslim religion $P=0.033$, primary level of education $P=0.005$, and secondary level of education $P=$ 0.038. Sociodemographic details are as shown in Table 1.

3.1. Organ Affected by Stroke. One thousand two hundred and forty-four (77.0\%) participants comprising 885 (76.2\%) and $359(78.9 \%)$ from urban and rural areas, respectively, did not recognize the brain as the organ affected by stroke. Substantial proportions of participants also believed other organs were the predominant focus of strokes including the heart $(N=417$; urban 21.9\%; rural 35.8\%; $P<0.001)$, lungs $(N=64$; urban 2.8\%; rural 7.0\%; $P<0.001)$, liver $(N=57$; urban 2.2\%; rural 6.8\%; $P<0.001)$, and kidneys $(N=73$; urban 2.2\%; rural 10.6\%; $P<0.001)$. Mentioning the brain as the correct organ affected in stroke was associated with good knowledge of stroke warning signs (OR 1.53; 95\% CI 1.132.07) at bivariate logistic regression but not by multivariable logistic regression.

3.2. Risk Factors for Stroke. Four hundred and thirty-six (27\%; 74.5\% urban) participants out of 1616 said they knew stroke risk factors. Two hundred and thirteen (48.9\%) knew at least one risk factor, 215 (49.3\%) knew 2-4 risk factors, and $8(1.8 \%)$ knew 5 or more risk factors. The most common risk factor identified by 244 (56\%) participants was hypertension (63.7\% urban; 33.3\% rural; $P<0.001$ ) followed by stress 224 
TABLE 1: Sociodemographic characteristics of the study participants.

\begin{tabular}{|c|c|c|c|c|}
\hline Characteristics & $\begin{array}{c}\text { Total } N=1616 \\
\text { Number }(\%)\end{array}$ & $\begin{array}{c}\text { Urban (Nansana) } \\
\text { Number }(\%)\end{array}$ & $\begin{array}{c}\text { Rural (Busukuma) } \\
\text { Number (\%) }\end{array}$ & $P$ value \\
\hline \multicolumn{5}{|l|}{ Gender } \\
\hline Male & $510(31.6)$ & $326(28.1)$ & $184(40.4)$ & 0.004 \\
\hline Female & $1,106(68.4)$ & $835(71.9)$ & $271(59.6)$ & $<0.001$ \\
\hline \multicolumn{5}{|l|}{ Age group (years) } \\
\hline Teenagers $<20$ & $56(3.5)$ & $48(4.1)$ & $8(1.8)$ & 0.761 \\
\hline Young adults (20-39) & $853(52.8)$ & $619(53.3)$ & $234(51.4)$ & 0.698 \\
\hline Middle aged adults (40-59) & $500(30.9)$ & $368(31.7)$ & $132(29.0)$ & 0.618 \\
\hline Elderly/aged (60-80) & $207(12.8)$ & $126(10.9)$ & $81(17.8)$ & 0.224 \\
\hline Mean age & $39.6 \pm 15.4$ & $38.8 \pm 14.8$ & $41.5 \pm 16.6$ & \\
\hline \multicolumn{5}{|l|}{ Religion } \\
\hline Catholic & $503(31.1)$ & $345(29.7)$ & $157(34.5)$ & 0.274 \\
\hline Protestant & $480(29.7)$ & $313(27.0)$ & $167(36.7)$ & 0.028 \\
\hline Muslim & $357(22.1)$ & $299(25.7)$ & $58(12.8)$ & 0.033 \\
\hline Pentecostal (born again) & $207(12.8)$ & $151(13.0)$ & $57(12.5)$ & 0.925 \\
\hline Other & $69(4.3)$ & $53(4.6)$ & $16(3.5)$ & 0.806 \\
\hline \multicolumn{5}{|l|}{ Highest level of education } \\
\hline Tertiary & $133(8.2)$ & $89(7.7)$ & $56(12.3)$ & 0.361 \\
\hline Secondary & $638(39.5)$ & $475(40.9)$ & $224(49.2)$ & 0.038 \\
\hline Primary & $699(43.3)$ & $502(43.2)$ & $136(29.9)$ & 0.005 \\
\hline Never attended school & $146(9.0)$ & $95(8.2)$ & $39(8.6)$ & 0.794 \\
\hline \multicolumn{5}{|l|}{ Marital status } \\
\hline Married & $986(61.0)$ & $712(61.3)$ & $274(60.2)$ & 0.773 \\
\hline Separated (not divorced) & $199(12.3)$ & $146(12.6)$ & $53(11.7)$ & 0.860 \\
\hline Divorced & $52(3.2)$ & $23(2.0)$ & $29(6.4)$ & 0.439 \\
\hline Single (never married) & $226(14.0)$ & $169(14.5)$ & $57(12.5)$ & 0.703 \\
\hline Widowed & $153(9.5)$ & $111(9.6)$ & $42(9.2)$ & 0.937 \\
\hline
\end{tabular}

(51.4\%; 53.2\% urban; $46.0 \%$ rural). None of the participants identified atherosclerosis and oral contraceptives as risk factors. The other risk factors identified are as shown in Table 2. At multivariable logistic regression, good knowledge of stroke risk factors was associated with tertiary level of education (OR 5.96; 95\% CI 2.94-12.06) and self-reported diabetes (OR; 1.84; 95\% CI 1.04-3.25).

3.3. Warning Symptoms of Stroke. Table 3 shows the profile of participant identified stroke warning signs. Most $(1,214$, 75.1\%) participants did not know any stroke warning signs. Of the minority that knew stroke warning signs $(N=402)$, 162 (40.3\%) knew 1 warning sign, 228 (56.7\%) knew 2-4 warning signs, and $12(3.0 \%)$ knew 5 or more warning signs. At multivariable logistic regression, good knowledge of stroke warning signs was associated with tertiary level of education (OR 4.29; 95\% CI 2.13-8.62) and self-reported diabetes (OR $1.97 ; 95 \%$ CI 1.18-3.32).

3.4. Concern about Having a Stroke, Prevention, Recurrence, and Effect on Activities of Daily Living. Table 4 shows the participants' responses to their own possibility of having a stroke and their knowledge as to whether stroke is preventable or can occur more than once. There was a significant difference in proportions between urban and rural responses regarding participants who had not thought about stroke over the past two years $P=0.017$, had thought about stroke over the past two years $P<0.001$, had thought that there is no chance of having a stroke in a life time $P=0.006$, had thought that stroke is not preventable $P<0.001$, and had thought that stroke cannot occur more than once $P=0.043$. All the participants thought that stroke would have an effect on the activities of daily living like driving a car, dressing, use of a toilet, and sustaining a job.

3.5. Planned Response to a Stroke Event. When offered choices of a planned response to a stroke event, eightyfive percent of the participants (86.1\% urban; $82.9 \%$ rural) reported that they would go to hospital should they or their relative experience sudden symptoms suggestive of a stroke, whilst only $0.7 \%$ ( $0.3 \%$ urban; $1.8 \%$ rural; $P=0.003)$ would combine going to hospital with tradition. However, $0.7 \%$ would call a general practitioner or family doctor and $6.9 \%$ ( $8 \%$ urban; $4 \%$ rural; $P=0.004$ ) would ask family members or relatives to help, whilst $6.8 \%, 0.5 \%, 1.7 \%$, and $0.8 \%$, respectively, would self-medicate, visit alternative health care providers (herbal medicine, traditional healers), seek spiritual healing, or invite a physiotherapist. 
TABLE 2: Stroke risk factors identified by participants (multiple responses).

\begin{tabular}{|c|c|c|c|c|}
\hline & $\begin{array}{c}\text { Total } 1616 \\
\text { Number }(\%)\end{array}$ & $\begin{array}{c}\text { Urban } \\
\text { Number }(\%)\end{array}$ & $\begin{array}{c}\text { Rural } \\
\text { Number (\%) }\end{array}$ & $\begin{array}{c}\text { Difference between regions }\left(x^{2}\right) \\
P \text { value }\end{array}$ \\
\hline \multicolumn{5}{|c|}{ Do you know any stroke risk factors? } \\
\hline No & $1180(73.0)$ & $836(72.0)$ & $344(75.6)$ & \\
\hline Yes & $436(27.0)$ & $325(28.0)$ & $111(24.4)$ & 0.143 \\
\hline If yes & $436(27.0)$ & & & \\
\hline Old age & $55(12.6)$ & $20(6.2)$ & $35(31.5)$ & $<0.001$ \\
\hline Diabetes & $65(14.9)$ & $44(13.5)$ & $21(18.9)$ & 0.169 \\
\hline Heart disease & $18(4.1)$ & $14(4.3)$ & $4(3.6)$ & 0.748 \\
\hline Obesity & $24(5.5)$ & $19(5.9)$ & $5(4.5)$ & 0.593 \\
\hline Stress & $224(51.4)$ & $173(53.2)$ & $51(46.0)$ & 0.185 \\
\hline Poor hygiene & $3(0.7)$ & $2(0.6)$ & $1(0.9)$ & 1.000 \\
\hline Cancer & $5(1.2)$ & $4(1.2)$ & $1(0.9)$ & 1.000 \\
\hline Bad diet & $129(29.6)$ & $101(31.0)$ & $28(25.2)$ & 0.244 \\
\hline Hypertension & $244(56.0)$ & $207(63.7)$ & $37(33.3)$ & $<0.001$ \\
\hline Cigarette smoking & $3(0.7)$ & $2(0.6)$ & $1(0.9)$ & 1.000 \\
\hline Alcohol & $15(3.4)$ & $11(3.4)$ & $4(3.6)$ & 1.000 \\
\hline High cholesterol & $53(12.2)$ & $48(14.8)$ & $5(4.5)$ & 0.004 \\
\hline Genetics (hereditary) & $3(0.7)$ & $2(0.6)$ & $1(0.9)$ & 1.000 \\
\hline Lack of exercise & $112(25.7)$ & $89(27.4)$ & $23(20.7)$ & 0.165 \\
\hline Headache or migraine & $2(0.5)$ & $1(0.3)$ & $1(0.9)$ & 0.445 \\
\hline Tremors & $6(1.4)$ & $6(1.9)$ & $0(0.0)$ & 0.149 \\
\hline Demons & $4(0.9)$ & $3(0.9)$ & $1(0.9)$ & 0.983 \\
\hline Witchcraft & $4(0.9)$ & $2(0.6)$ & $2(1.8)$ & 0.258 \\
\hline God's will & $26(6.0)$ & $14(4.3)$ & $12(10.8)$ & 0.013 \\
\hline Angry ancestral spirits & $4(0.9)$ & $4(1.2)$ & $0(0.0)$ & 0.240 \\
\hline
\end{tabular}

The risk factors required a yes/no response.

3.6. Source of Information about Stroke. Only 402 (24.9\%) participants, $70.4 \%$ from the urban area, had heard about stroke. The commonest source of information on stroke from multiple responses was friends/relatives reported by 270 (67.2\%) participants $(62.5 \%$ urban; 78.2 rural; $P=0.002)$ followed by health care providers reported by 154 (38.3\%) participants (46.3\% urban; $19.3 \%$ rural; $P<0.001)$. However, $6.2 \%$ reported newspapers as their source of stroke information, whilst $19.9 \%, 8.0 \%$, and $2.0 \%$, respectively, reported radio (22.6\% urban; $13.45 \%$ rural; $P=0.036$ ), television (10.3\% urban; $2.5 \%$ rural; $P=0.009$ ), and other electronic media such as internet. None of the rural participants used other forms of electronic media besides radio and television.

\section{Discussion}

Noncommunicable diseases are fast becoming a serious public health concern in developing countries [1-3] such as Uganda. Lack of knowledge of stroke risk factors contributes to the rising incidence of stroke amongst Africans [5-7], and it is imperative that educational campaigns target both general and high risk members of the population with accurate and appropriate information. To our knowledge, this is the first study to establish the perception and knowledge about stroke from urban and rural populations in Uganda. Main findings are that stroke knowledge is poor with some groups being particularly uninformed, individuals do not personally believe stroke is something that can actually happen to them, and few individuals see primary health care workers as a resource for stroke prevention or care. Such information can set the stage for future strategies and campaigns to promote stroke knowledge and facilitate stroke prevention initiatives.

4.1. Poor Knowledge regarding Stroke. There is lack of knowledge about stroke among the public even in developed countries like the United States [10] and Australia [20]. Consistent with other reports, among our Ugandan sample, perception and knowledge of stroke were poor $[7,9,10,12$, 20]. Almost three quarters of participants wrongly identified the heart as the organ affected in stroke. Association of stroke with heart disease by the participants in this study might have been informed by the local belief that the heart is a major organ of thinking.

Multiple studies have reported inadequate knowledge of stroke outside the western industrialized world [10]. The lack of information on risk factors and warning signs for stroke in our study was much higher than in other samples $[10,11,20,22]$. While this knowledge gap is daunting, it also illuminates multiple potential opportunities to improve general knowledge especially among those at high risk for 
TABLE 3: Stroke warning symptoms identified by participants (multiple responses).

\begin{tabular}{|c|c|c|c|c|}
\hline & $\begin{array}{c}\text { Total } 1616 \\
\text { Number }(\%)\end{array}$ & $\begin{array}{c}\text { Urban } \\
\text { Number (\%) }\end{array}$ & $\begin{array}{c}\text { Rural } \\
\text { Number }(\%)\end{array}$ & $\begin{array}{c}\text { Difference between regions }\left(x^{2}\right) \\
P \text { value }\end{array}$ \\
\hline \multicolumn{5}{|l|}{ Do you know any stroke warning signs } \\
\hline No & $1,214(75.1)$ & $878(75.6)$ & $336(73.9)$ & \\
\hline Yes & $402(24.9)$ & $283(24.4)$ & $119(26.2)$ & 0.457 \\
\hline If yes & $402(24.9)$ & & & \\
\hline Dizziness & $95(23.6)$ & $67(23.7)$ & $28(23.5)$ & 0.975 \\
\hline Headache & $65(16.2)$ & $51(18.0)$ & $14(11.8)$ & 0.120 \\
\hline Tiredness & $66(16.4)$ & $50(17.7)$ & $16(13.7)$ & 0.297 \\
\hline Shortness of breath & $39(9.7)$ & $22(7.8)$ & $17(14.3)$ & 0.044 \\
\hline Nausea/vomiting & $4(1.0)$ & $3(1.1)$ & $1(0.84)$ & 0.839 \\
\hline Weakness of one side of the body & $105(26.1)$ & $78(27.6)$ & $27(22.7)$ & 0.310 \\
\hline Paralysis on one side of the body & $115(28.6)$ & $97(34.3)$ & $18(15.1)$ & $<0.001$ \\
\hline $\begin{array}{l}\text { Numbness tingling sensation or dead sensation of } \\
\text { any part of body }\end{array}$ & $36(9.0)$ & $28(9.9)$ & $8(6.7)$ & 0.309 \\
\hline $\begin{array}{l}\text { Numbness tingling sensation or dead sensation on } \\
\text { one side of the body }\end{array}$ & $17(4.2)$ & $16(5.7)$ & $1(0.8)$ & 0.029 \\
\hline Blurred/double /loss of vision & $11(2.7)$ & $8(2.8)$ & $3(2.5)$ & 0.864 \\
\hline Sudden difficulty in speaking/understanding/reading & $9(2.2)$ & $9(3.2)$ & $0(0.00)$ & 0.063 \\
\hline Fever/sweating & $39(9.7)$ & $24(8.5)$ & $15(12.6)$ & 0.202 \\
\hline Chest pain/tightness & $15(3.7)$ & $13(4.6)$ & $2(1.7)$ & 0.248 \\
\hline Weakness of any part of the body & $30(7.5)$ & $15(5.3)$ & $15(12.6)$ & 0.011 \\
\hline Paralysis of any part of body & $70(17.4)$ & $35(12.4)$ & $35(29.4)$ & $<0.001$ \\
\hline Fainting/black out/collapse & $26(6.5)$ & $23(8.1)$ & $3(2.5)$ & 0.037 \\
\hline Others (specify) & $31(7.7)$ & $21(7.4)$ & $10(8.4)$ & 0.736 \\
\hline
\end{tabular}

Warning symptoms required yes/no response.

stroke and low level of education and help individuals in the future both reduce stroke risk and reduce complications should a stroke occur.

Less than $1 \%$ of participants thought demons, witchcraft, or angry ancestral spirits caused stroke and a similar percentage preferred traditional healers and herbal medication in the event of a stroke. Most Ugandans have an identified religion with Christians comprising $85.2 \%$ and Muslims about $12 \%$ of the population [23]. Though cultural belief in the causation of ill health and misfortune through the activity of witchcraft is reportedly still quite common in the area of HIV/AIDS [24], our study's findings were in contrast to this regarding the cause of stroke and preferred response to a stroke event. There was however a significant difference in the number of participants from the rural area that preferred a combination of hospital and tradition compared to participants from the urban area.

4.2. Stroke as a Personal and Potentially Relevant Disorder. While many participants in our study endorsed the fact that stroke could have serious and far-reaching effects, the majority $(>75 \%)$ said that they had never thought about stroke before and opined that there was no chance or low chance of them having a stroke in the last 12 months or in a lifetime. It is clear that many individuals in our sample did not conceptualize stroke as a disorder that was relevant to them personally, and stroke awareness campaigns will have to address this barrier.

4.3. Resources for Stroke Information and Care. The minority of individuals in our sample that had heard about stroke depended more on relatives/friends than health personnel for information on stroke. This upheld the findings of Sug Yoon et al. [20] among an Australian urban population. Among the urban population, health care providers were the next identified source of stroke information $(45.8 \%)$ while they ranked third (10.6\%) after radio $(21.2 \%)$ among the rural population. Our findings may imply that health care givers are ineffective in reaching rural populations with stroke information. The higher proportion of participants who obtained stroke information from electronic mediaradio may imply that the rural population may be better served by receiving information on stroke through the radio.

Majority of the participants $(>80 \%)$, from either the urban or rural areas, preferred going to hospital when they or someone close to them had experienced symptoms of stroke. Comparable responses were seen in other studies $[22,25,26]$ except in Nigerian subjects [9] where only $22.4 \%$ of them mentioned that they would visit a hospital and the most preferred response $(34.9 \%)$ was calling a general 
TABLE 4: Participants' concern about having a stroke, if preventable, and recurrence.

\begin{tabular}{|c|c|c|c|c|}
\hline Concern about having a stroke & $\begin{array}{c}\text { Total } 1616 \\
\text { Number (\%) }\end{array}$ & $\begin{array}{c}\text { Urban } \\
\text { Number (\%) }\end{array}$ & $\begin{array}{c}\text { Rural } \\
\text { Number (\%) } \\
\end{array}$ & $P$ value \\
\hline \multicolumn{5}{|c|}{ Have you thought about stroke over the recent past 2 years? } \\
\hline No & $431(26.7)$ & $354(30.5)$ & $78(17.1)$ & 0.017 \\
\hline Yes & $1,185(73.3)$ & $807(69.5)$ & $377(82.9)$ & $<0.001$ \\
\hline \multicolumn{5}{|l|}{ If yes } \\
\hline \multicolumn{5}{|c|}{ Possibility of you having a stroke in next 12 months? } \\
\hline No chance & $463(39.1)$ & $299(37.1)$ & $164(43.5)$ & 0.178 \\
\hline Low chance & $350(29.5)$ & $240(29.7)$ & $110(29.2)$ & 0.924 \\
\hline Moderate chance & $238(20.1)$ & $173(21.4)$ & $65(17.2)$ & 0.473 \\
\hline High chance & $134(11.3)$ & $95(11.8)$ & $39(10.3)$ & 0.804 \\
\hline \multicolumn{5}{|c|}{ Have you thought about stroke before? } \\
\hline No & $348(21.5)$ & $270(23.3)$ & $77(16.9)$ & 0.231 \\
\hline Yes & $1,268(78.5)$ & $891(76.7)$ & $378(83.1)$ & 0.011 \\
\hline \multicolumn{5}{|l|}{ If yes } \\
\hline \multicolumn{5}{|c|}{ Possibility of you having a stroke in your lifetime? } \\
\hline No chance & $432(34.1)$ & $269(30.2)$ & $163(43.1)$ & 0.006 \\
\hline Low chance & $381(30.0)$ & $279(31.3)$ & $102(27.0)$ & 0.418 \\
\hline Moderate chance & $273(21.5)$ & $210(23.6)$ & $63(16.7)$ & 0.246 \\
\hline High chance & $182(14.4)$ & $133(14.9)$ & $49(13.0)$ & 0.746 \\
\hline \multicolumn{5}{|l|}{ Is stroke preventable } \\
\hline No & $500(30.9)$ & $310(26.7)$ & $190(41.8)$ & $<0.001$ \\
\hline Yes & $638(39.5)$ & $470(40.5)$ & $168(36.9)$ & 0.413 \\
\hline Do not know & $478(29.6)$ & $381(32.8)$ & $97(21.3)$ & 0.028 \\
\hline \multicolumn{5}{|c|}{ Can a person have stroke more than once? } \\
\hline No & 467 (28.9) & $306(26.4)$ & $161(35.4)$ & 0.043 \\
\hline Yes & $715(44.3)$ & $511(44.0)$ & $204(44.8)$ & 0.846 \\
\hline Do not know & $434(26.9)$ & $344(29.6)$ & $90(19.8)$ & 0.064 \\
\hline
\end{tabular}

practitioner/family doctor. In our study, less than $1 \%$ of participants from either urban or rural area preferred calling a general practitioner/family doctor. This might be because, for the majority of the participants, it sounds probably most rational to rush stroke patients to general hospitals where they thought a medical doctor will be available to attend to the stroke patient. The doctor available at the hospital did not have to be known to them and the treatment if available was done at no additional cost. However, compared to the very rare practice of the study population having a family doctor or even knowing a general practitioner and the additional cost involved in calling one under a private arrangement was probably the reason for their choice.

\section{Conclusion}

This first report of a large Ugandan general population sample found that individuals had extremely limited knowledge of stroke and did not feel that stroke as a disorder had any personal relevance to them. Primary health care workers were not identified as a key resource in stroke care. These results indicate a need to increase public stroke awareness in Uganda. Local and regional healthcare workers are resources that are not optimally used and represent an opportunity to improve stroke prevention and stroke community response.

\section{Conflict of Interests}

The authors declare that they have no conflict of interests regarding the publication of this paper.

\section{Authors' Contribution}

All authors made substantial contribution to conception and designing of the study and development of the data collection tools and data analysis. Jane Nakibuuka participated in data collection. All authors participated in drafting or revising the paper critically for important intellectual content and approval of the final version to be published.

\section{Acknowledgments}

This work was supported by Grant no. 5R24TW008886 supported by OGAC, NIH, and HRSA. Its contents are solely the responsibility of the authors and do not necessarily represent the official views of the supporting offices. The authors also would like to thank all study participants in 
Nansana Town Council and Busukuma subcounty for their valuable time and information. Mr. Joseph Sempa, the MEPICVD linked Project Coordinator Rhoda Namubiru, and the research team including the research assistants are also duly acknowledged for the technical input, support, providing the equipment, and assistance with carrying out the interviews, respectively.

\section{References}

[1] V. L. Feigin, C. M. M. Lawes, D. A. Bennett, and C. S. Anderson, "Stroke epidemiology: a review of population-based studies of incidence, prevalence, and case-fatality in the late 20th century," Lancet Neurology, vol. 2, no. 1, pp. 43-53, 2003.

[2] P. M. Dalal, S. Malik, M. Bhattacharjee et al., "Population-based stroke survey in Mumbai, India: incidence and 28-day case fatality," Neuroepidemiology, vol. 31, no. 4, pp. 254-261, 2008.

[3] P. M. Dalal and M. Bhattacharjee, "Stroke epidemic in India: hypertension-stroke control programme is urgently needed," Journal of Association of Physicians of India, vol. 55, pp. 689-691, 2007.

[4] V. L. Feigin, M. H. Forouzanfar, R. Krishnamurthi et al., "Global and regional burden of stroke during 1990-2010: findings from the Global Burden of Disease Study 2010," The Lancet, vol. 383, no. 9913, pp. 245-255, 2014.

[5] G. A. Mensah, "Epidemiology of stroke and high blood pressure in Africa," Heart, vol. 94, no. 6, pp. 697-705, 2008.

[6] R. O. Akinyemi, O. S. Ogah, R. F. Ogundipe et al., "Knowledge and perception of stroke amongst hospital workers in an African community," European Journal of Neurology, vol. 16, no. 9, pp. 998-1003, 2009.

[7] C. H. Njoku and A. B. Aduloju, "Stroke in Sokoto, Nigeria: a five year retrospective study," Annals of African Medicine, vol. 3, no. 2, pp. 73-76, 2004.

[8] N. Stroebele, F. Müller-Riemenschneider, C. H. Nolte, J. MüllerNordhorn, A. Bockelbrink, and S. N. Willich, "Knowledge of risk factors, and warning signs of stroke: a systematic review from a gender perspective," International Journal of Stroke, vol. 6, no. 1, pp. 60-66, 2011.

[9] O. Ayanniyi, O. Akande, and A. F. Mustapha, "Knowledge and perception of stroke among adults in Osogbo, Nigeria," African Journal of Medicine and Medical Sciences, vol. 35, no. 4, pp. 447$452,2006$.

[10] S. P. Jones, A. J. Jenkinson, M. J. Leathley, and C. L. Watkins, "Stroke knowledge and awareness: an integrative review of the evidence," Age and Ageing, vol. 39, no. 1, pp. 11-22, 2009.

[11] A. Borhani Haghighi, A. A. Karimi, A. Amiri, and F. Ghaffarpasand, "Knowledge and attitude towards stroke risk factors, warning symptoms and treatment in an Iranian population," Medical Principles and Practice, vol. 19, no. 6, pp. 468-472, 2010.

[12] A. Hickey, A. O'Hanlon, H. McGee et al., "Stroke awareness in the general population: knowledge of stroke risk factors and warning signs in older adults," BMC Geriatrics, vol. 9, no. 1, article 35, 2009.

[13] G. Mshana, K. Hampshire, C. Panter-Brick, and R. Walker, "Urban-rural contrasts in explanatory models and treatmentseeking behaviours for stroke in Tanzania," Journal of Biosocial Science, vol. 40, no. 1, pp. 35-52, 2008.

[14] Z. Bham and E. Ross, "Traditional and Western medicine: cultural beliefs and practices of South African Indian Muslims with regard to stroke," Ethnicity and Disease, vol. 15, no. 4, pp. 548$554,2005$.

[15] G. L. Hundt, M. Stuttaford, and B. Ngoma, "The social diagnostics of stroke-like symptoms: healers, doctors and prophets in agincourt, limpopo province, South Africa," Journal of Biosocial Science, vol. 36, no. 4, pp. 433-443, 2004.

[16] C. Comoro, S. E. D. Nsimba, M. Warsame, and G. Tomson, "Local understanding, perceptions and reported practices of mothers/guardians and health workers on childhood malaria in a Tanzanian district-implications for malaria control," Acta Tropica, vol. 87, no. 3, pp. 305-313, 2003.

[17] V. R. Kamat, “I thought it was only ordinary fever!' cultural knowledge and the micropolitics of therapy seeking for childhood febrile illness in Tanzania," Social Science and Medicine, vol. 62, no. 12, pp. 2945-2959, 2006.

[18] M. Green, "Public reform and the privatisation of poverty: some institutional determinants of health seeking behaviour in southern Tanzania," Culture, Medicine and Psychiatry, vol. 24, no. 4, pp. 403-430, 2000.

[19] P. Tibandebage and M. Mackintosh, "The market shaping of charges, trust and abuse: health care transactions in Tanzania," Social Science and Medicine, vol. 61, no. 7, pp. 1385-1395, 2005.

[20] S. Sug Yoon, R. F. Heller, C. Levi, and J. Wiggers, "Knowledge and perception about stroke among an Australian urban population," BMC Public Health, vol. 1, no. 1, article 14, 2001.

[21] S. S. Yoon, R. F. Heller, C. Levi, J. Wiggers, and P. E. Fitzgerald, "Knowledge of stroke risk factors, warning symptoms, and treatment among an Australian urban population," Stroke, vol. 32, no. 8, pp. 1926-1930, 2001.

[22] J. D. Pandian, A. Jaison, S. S. Deepak et al., "Public awareness of warning symptoms, risk factors, and treatment of stroke in Northwest India," Stroke, vol. 36, no. 3, pp. 644-648, 2005.

[23] "Ugandan demographics profile 2013," http://www.indexmundi.com/uganda/demographics_profile.html.

[24] G. Bodeker, G. Carter, G. Burford, and M. Dvorak-Little, "HIV/ AIDS: traditional systems of health care in the management of a global epidemic," Journal of Alternative and Complementary Medicine, vol. 12, no. 6, pp. 563-576, 2006.

[25] K. Parahoo, K. Thompson, M. Cooper, M. Stringer, E. Ennis, and P. McCollam, "Stroke: awareness of the signs, symptoms and risk factors-a population-based survey," Cerebrovascular Diseases, vol. 16, no. 2, pp. 134-140, 2003.

[26] M. J. Reeves, J. G. Hogan, and A. P. Rafferty, "Knowledge of stroke risk factors and warning signs among Michigan adults," Neurology, vol. 59, no. 10, pp. 1547-1552, 2002. 


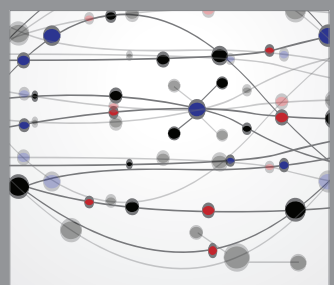

The Scientific World Journal
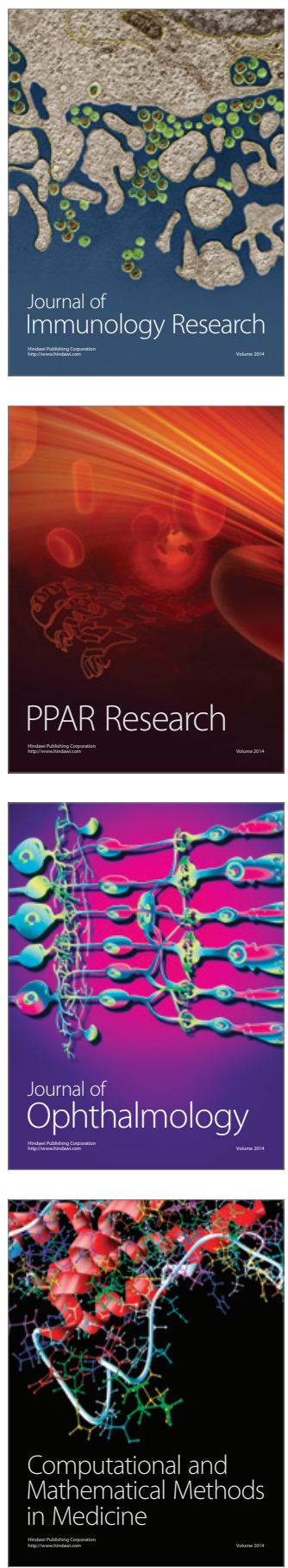

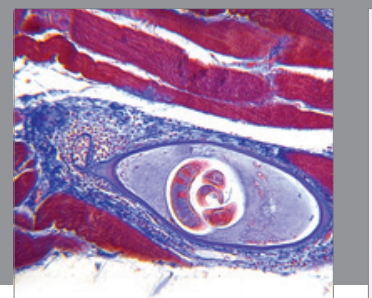

Gastroenterology

Research and Practice
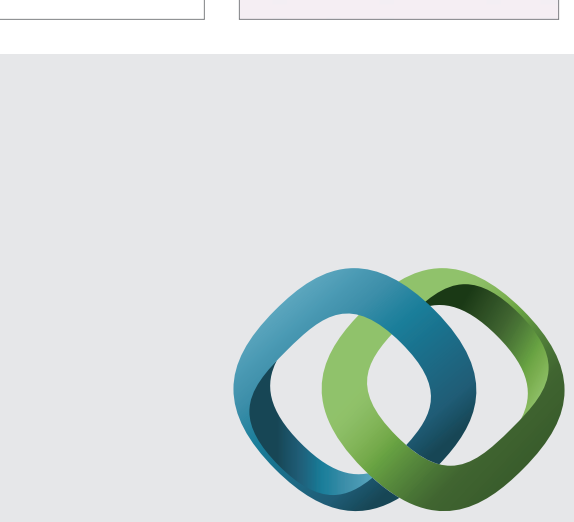

\section{Hindawi}

Submit your manuscripts at

http://www.hindawi.com
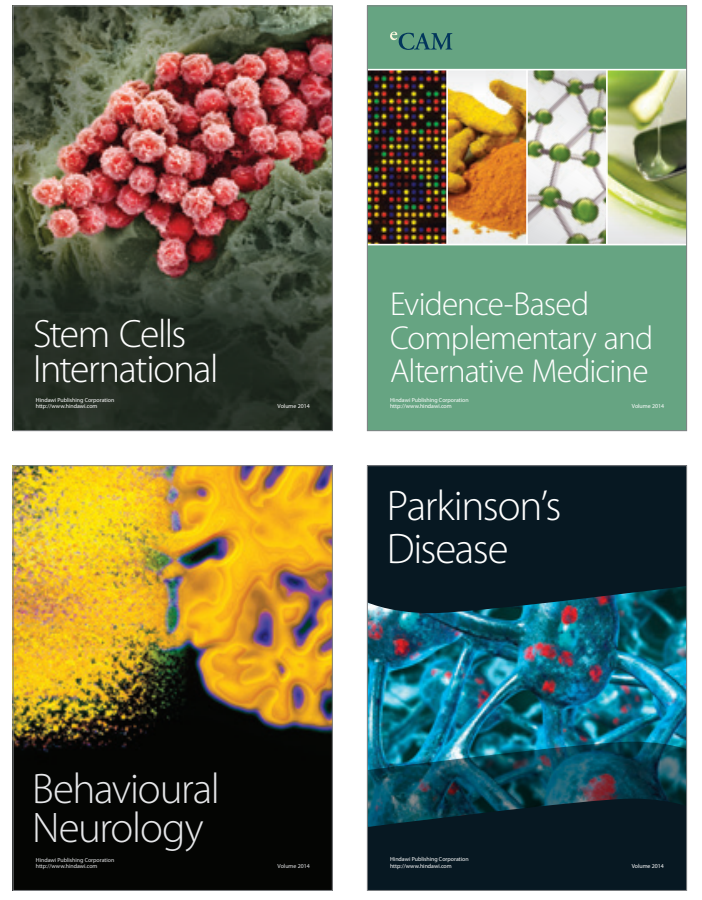
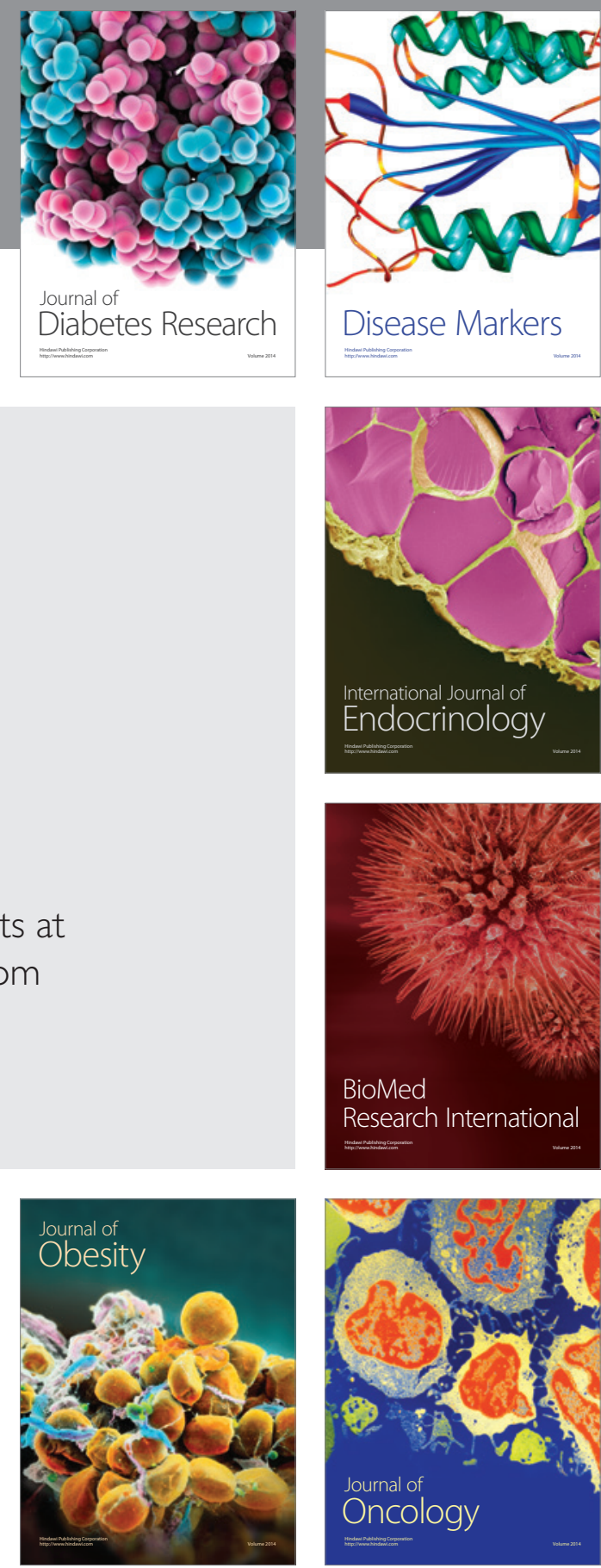

Disease Markers
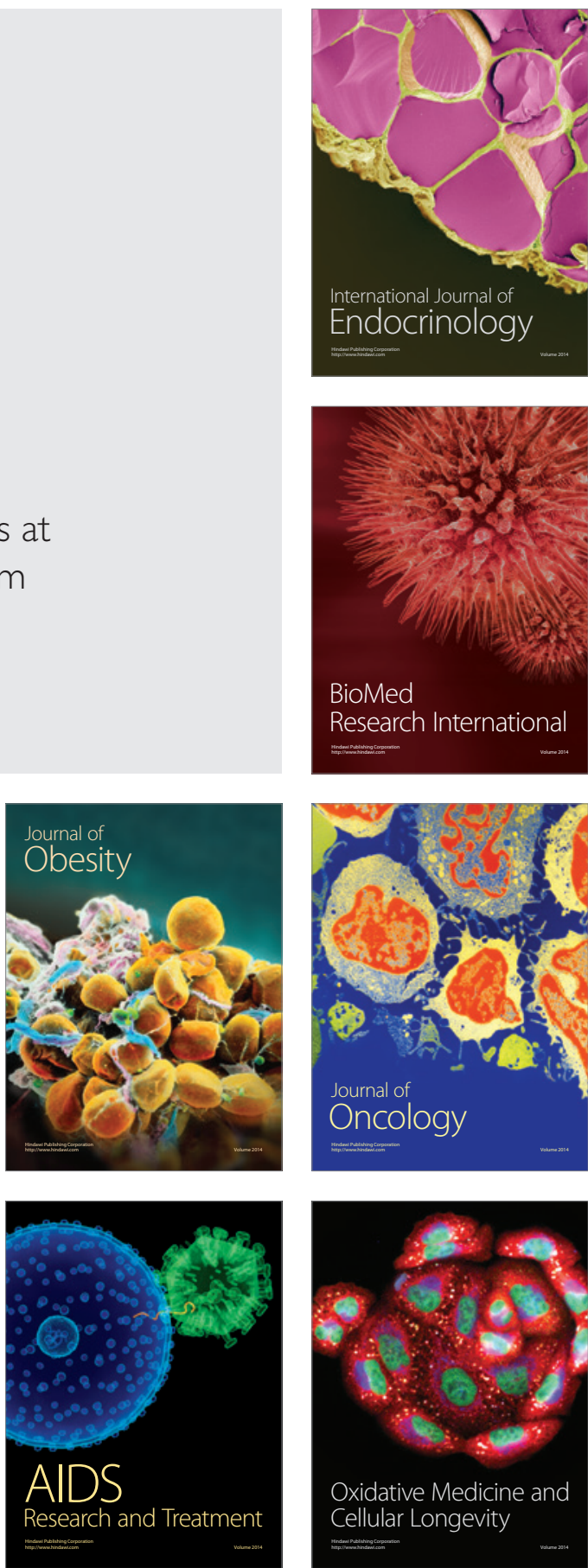